\title{
Primary testicular mucinous cystadenoma: Case report and literature review
}

\author{
Mário Maciel de Lima Jr, MD;* Mário Maciel de Lima, MD; Fabiana Granja, PhD \\ "Department of Urology at Coronel Mota Hospital in Roraima State, Brazil; ' Biodiversity Research Center atthe Federal Universityof Roraima (CBio/UFRR), Boa Vista, Brazil
}

Cite as: Can Urol Assoc J 2015;9(11-12):E814-6. http://dx.doi.org/10.5489/cuaj.3218 Published online November 4, 2015.

\section{Abstract}

Testicular mucinous cystadenomas are rare in urological practice, and their histogenesis, course and management are debated. We report a primary testicular mucinous cystadenoma in a 54-year old male who presented with left testicular swelling and pain. He denied having a history of cryptorchidism, testicular trauma, infections, urinary complaints, or febrile illnesses. He did not have diabetes, but was on treatment for hypertension. The patient underwent a left inguinal radical orchiectomy, and histological examination of the resected tumour confirmed a primary testicular mucinous cystadenoma. The patient had an uneventful recovery, and is being followed up. Conclusively, urologists need to maintain a high index of suspicion of these tumours and their differentiation from metastatic tumours to ensure optimal therapeutic outcomes.

\section{Introduction}

Ovarian-type, primary surface epithelial tumours of the testes are rare in urological practice. ${ }^{1}$ Their cause, disease biology and ideal management remain obscure. These tumours may raise suspicion of a metastatic disease, but have a good prognosis. ${ }^{2}$ We present a case report of this condition, along with literature review.

\section{Case report}

A 54-year old male presented to the urology clinic with complaints of progressive swelling and heaviness of the left testicle, with occasional pain for 8 months. He denied a history of cryptorchidism, testicular trauma, infections, urinary complaints, or febrile illnesses. He did not have diabetes, but was on treatment for hypertension with tab chlorthalidone $15 \mathrm{mg}$ OD. His family history was unremarkable.

On physical examination, his left testicle was swollen, hard and tender with a normal right testicle. The spermatic cords appeared normal on both sides, and inguinal lymph nodes were not palpable. There was no hydrocele or urethral discharge. Routine blood tests, serum alpha-fetoprotein (AFP) and $\beta$-human chorionic gonadotrophin ( $\beta$-HCG) estimation were normal. Scrotal ultrasonography revealed a nodular lesion of $3.1 \times 2.3 \times 2.0 \mathrm{~cm}$, in the posterior region of the left testicle of the patient (Fig. 1).

Prompted by suspicion of a testicular tumour, we performed a computed tomography scan to obtain a more detailed view (Fig. 2). A left inguinal radical orchiectomy was performed on the patient, under spinal anesthesia. The resected tissue was fixed with $10 \%$ neutral buffered formalin and processed for paraffin embedding, sectioning and hematoxylin-eosin staining. Microscopic examination of the resected tissue revealed a unilocular testicular cyst with fibrous walls, measuring $35 \mathrm{~mm}$, lined by columnar epithelium with a gelatinous content (Fig. 3).

The postoperative period was uneventful and the patient was discharged after surgery. Testicular sonograms and serum tumour marker levels remained normal at the 3 monthly follow-up appointments after surgery. Results of annual colonoscopy and endoscopy were also negative for disease recurrence and metastasis.

\section{Discussion}

Ovarian-like epithelial and stromal tumours can originate from testicular or paratesticular tissues. Their histologic origin is debated, and hypotheses suggest mesothelial metaplasia of tunica vaginalis, ${ }^{3}$ failure in total regression of Mullerian elements, or from unilateral teratoma cell differentiation. ${ }^{4}$ There are 6 subtypes of ovarian-like epithelial tumours, including the serous, mucinous, endometrioid, clear, transitional (Brenner), and squamous. Morphologically, these tumours range (in order of predominance) from cystadenomas to borderline tumours to carcinomas.

Mucinous cystadenoma is usually seen in older patients, with a median age of 54 years. ${ }^{4}$ These tumours could be benign, borderline, or follow a malignant course with metas- 


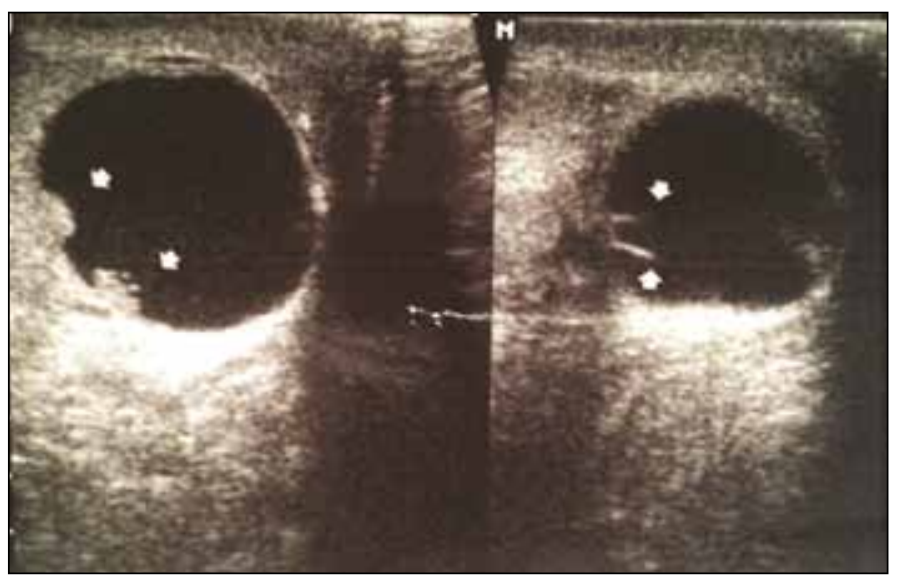

Fig. 1. Testicular ultrasonogram of the patient showing the nodular lesion (indicated by arrows) in the posterior region of left testicle.

tasis. Very few cases of primary mucinous tumours of testes and paratestes have been reported. Among these, 17 were primary testicular mucinous tumours and the rest were of para-testes. Eight of the reported primary testicular mucinous testicular tumours were cystadenomas, 13 were borderline tumours and 5 were mucinous carcinomas. ${ }^{4}$

Microscopically, the mucinous testicular tumours may exhibit thickening and fibrosis of cyst walls, dystrophic calcification, metaplastic ossification, mucin extravasation and cholesterol clefts. Studies have also reported degenerative and reactive changes, multinucleated giant cells, heavy infiltration with lymphocytes, plasma cells and hemosiderinladen macrophages. ${ }^{2,5}$ Teratomatous components, germ cell neoplasia and ovarian-type stroma are occasionally present. In isolated reports, a papillary pattern of arrangement of mucinous cells lining the tumour correlated with borderline disease or a tumour with low malignant potential. ${ }^{6}$

Testicular tumours are smaller and unilocular. The prominent location and symptomatology often lead to early detection. Most patients report painless testicular enlargement and occasional hydrocele. ${ }^{6}$ The tumour can lead to testicular atrophy, ${ }^{2}$ which may incidentally be detected during infertility workup. ${ }^{5}$

Metastatic tumours (mostly from colon, stomach, and rarely pancreas) are an important differential diagnosis with regard to ovarian-type surface epithelial tumours of the testes. These cases mostly occur in men over 50 years, about $10 \%$ of whom present with a unilateral testicular mass. ${ }^{2}$ Features suggest a metastatic origin, affecting testicular interstitium, vascular involvement, multifocality, and bilaterality of the tumours.

Nokubi and colleagues reported the utility of immunohistochemical staining in the diagnosis of testicular mucinous adenocarcinoma. ${ }^{4}$ Immunostaining for cytokeratin 7 , mucin 2 (MUC2), mucin 5AC (MUC5AC), and mucin 6 (MUC6) are useful in the differentiation of ovarian-type from metastatic ovarian tumours. Neoplastic epithelial cells within the

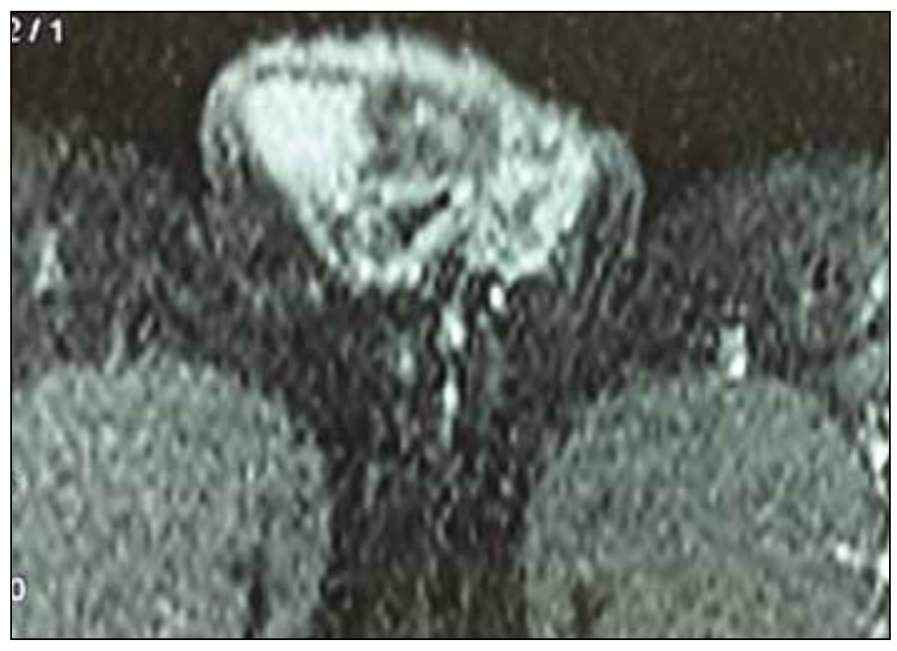

Fig. 2. A computed tomography scan of the testicle obtained prior to orchiectomy on the patient.

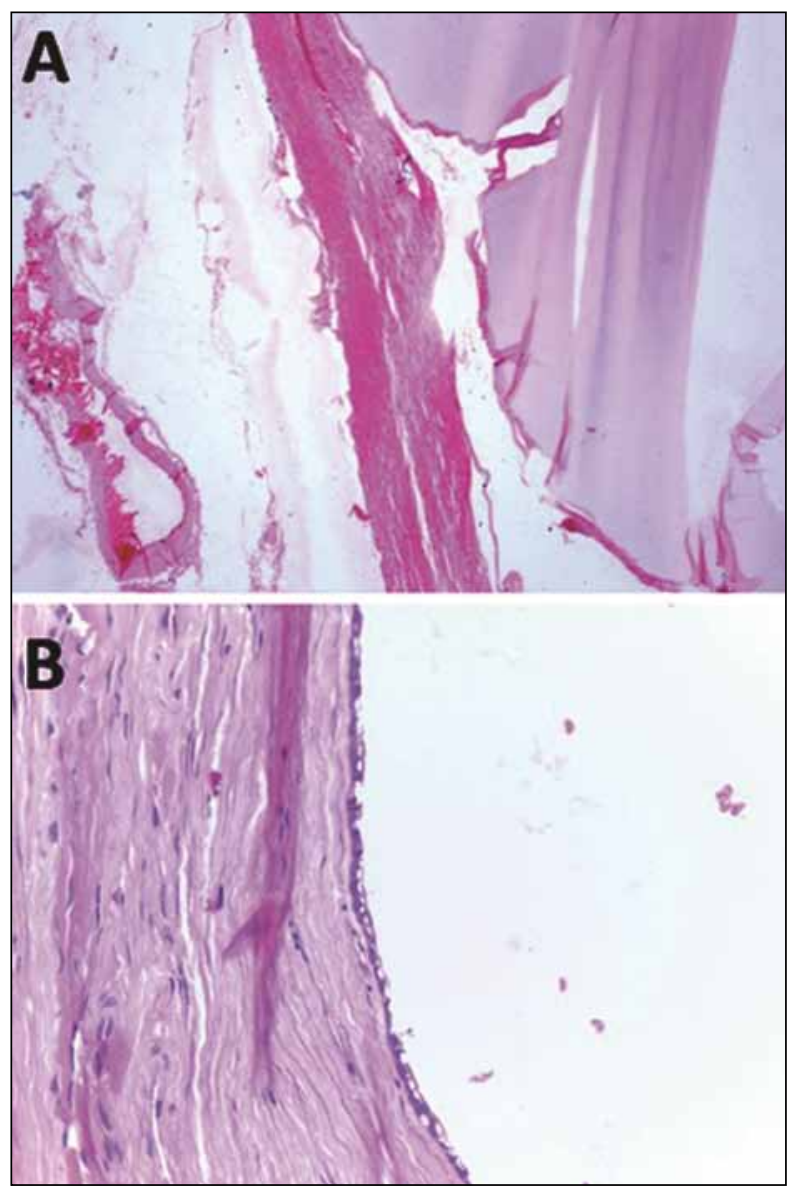

Fig. 3. Photomicrographs of hematoxylin \& eosin stained sections of the tumour material from the patient. (A) Note the presence of the fibrous cell wall, and mucinous material in the cyst (magnification, 2.5x). (B) Image showing the inner lining of the cyst, formed by nonciliated epithelium, interrupted by the cystic content (magnification 40x). 
tumour may show strong positivity for carcinoembryonic antigen (CEA), cytokeratins AE1-AE3, cytokeratin 19, cytokeratin 20, but could be negative for cytokeratin 7 , vimentin and CD117. Colorectal adenocarcinomas are mostly nonreactive to cytokeratin 7 and reactive to cytokeratin 20, while ovarian mucinous tumours are mostly reactive to both. ${ }^{7}$ Menon and colleagues reported immunoreactivity to pancytokeratin, cytokeratin 20 and CEA in a case of primary borderline mucinous testicular cystadenoma. ${ }^{8}$

Sonographic appearance of these tumours is often nonspecific and similar to those of other malignant tumours, such as teratomas. ${ }^{9}$ Peripheral or paratesticular localization, especially with the tunica vaginalis or tunica albuginea, often correlates with adenofibromas and other types of ovarian-type epithelial and stromal tumours. ${ }^{10}$ Radiological investigations can help to differentiate primary from metastatic tumours.

There is no current information on standardized staging schemes or optimal treatment of these tumours. Radical orchiectomy is the preferred surgical treatment for localized cystadenomas and borderline tumours, which generally do not recur or spread. Several groups described adjuvant chemotherapy with paclitaxel and carboplatin for ovarian tumours, and liposomal dauxorubicin or gemcitabine for relapsed disease. ${ }^{11,12}$ However, its utility in primary testicular mucinous adenomas remains to be substantiated.

Most cases of testicular mucinous adenomas do not have metastasis and have a good prognosis. ${ }^{2}$ Moreover, our patient did not display features of disease recurrence or metastasis, upon serial monitoring by tumour marker levels, testicular ultrasonography, screening colonoscopy and endoscopy.

\section{Conclusion}

Urologists need to maintain a high index of suspicion of these tumours and their differentiation from metastatic tumours to ensure optimal therapeutic outcomes.
Competing interests: The authors declare no competing financial or personal interests.

This paper has been peer-reviewed.

\section{References}

1. Henley JD, Ferry J, Ulbright TM. Miscellaneous rare paratesticular tumors. Semin Diagn Pathol 2000;17:319-39.

2. Funada $S$, Yoshida $T$, Ito $M$, et al. Primary borderline mucinous tumours of the testis: $A$ case report and literature review. Case Rep Oncol Med 2015;2015:863745.

3. Sundarasivarao D. The Müllerian vestiges and benign epithelial tumours of the epididymis. J Pathol Bacteriol 1953;66:417-32. http://dx.doi.org/10.1002/path.1700660213

4. Kellert E. An ovarian type pseudomucinous cystadenoma in the scrotum. Cancer 1959;12:187-90. http:// dx.doi.org/10.1002/1097-0142(195901/02)12:1<187::AID-CNCR2820120124>3.0.C0;2-H

5. Azuma T, Matayoshi Y, Nagase Y. Case report: Primary mucinous adenocarcinoma of the testis. Case Rep Med 2012;2012:685946.

6. Haupt HM, Mann RB, Trump DL, et al. Metastatic carcinoma involving the testis. Clinical and pathologic distinction from primary testicular neoplasms. Cancer 1984;54:709-14. hittp://dx.doi.org/10.1002/10970142(1984)54:4<709::AID-CNCR2820540419>3.0.C0;2-6

7. Menon S, Ahmed S, Desai S. Primary borderline mucinous neoplasm of the testis: A case report and literature review. Indian J Urol 2012;28:224-6. http://dx.doi.org/10.4103/0970-1591.98476

8. Woodward PJ, Sohaey R, O'Donoghue MJ, et al. From the archives of the AFIP: Tumors and tumorlike lesions of the testis—radiologic-pathologic correlation. Radiographics 2002;22:189-216. http://dx.doi. org/10.1148/radiographics.22.1.g02ja14189

9. Oyama $\mathrm{H}, \mathrm{Ogawa} \mathrm{M}$, Mikuriya $\mathrm{H}$, et al. Adenofibroma tumor of testicular tunica albuginea: A case report [in Japanese]. Hinyokika Kiyo 2001;47:661-3.

10. Vaughn DJ, Rizzo TA, Malkowicz SB. Chemosensitivity of malignant ovarian-type sufface epithelial tumor of testis. Urology 2005;66:658.e7-9. http://dx.doi.org/10.1016/j.urology.2005.03.032

11. Ali SN, Ledermann JA. New developments Current practice and new developments in ovarian cancer chemotherapy. Obstet Gynaecol 2007;9:265-9.

12. Ledermann JA, Kristeleit RS. Optimal treatment for relapsing ovarian cancer. Ann Oncol 2010;21:vii21822.

Correspondence: Dr. Mário Maciel de Lima Jr, Rua Levindo Inácio de Oliveira, 1547, Paraviana Boa Vista, RR, Brazil, CEP: 69307-272; mmli@@uol.com.br 